\title{
Hva er idrettspsykiatri?
}

\author{
$\AA ̊$ være en idrettsutøver betyr å påføre seg selv fysisk, mentalt og sosialt stress. Noen tåler dette bedre enn \\ andre. For å hjelpe dem som tilbringer store deler av tilværelsen innenfor idrett og toppidrett må det utvikles \\ spesifikk idrettspsykiatrisk kompetanse.
}

Finn Skårderud

finns@online.no

Fysisk aktivitet er sunt både for den fysiske og psykiske helsen (1). Men i den organiserte idretten belastes kropp og sinn på et vis som kan true helsen. Å vinne handler om å overskride grenser. Slike grenseoverskridelser fascinerer med sin eksistensielle tematikk omkring å seire og å tape, og de er $i$ dag en motor i medieindustrien. Der hvor grensene utfordres i prestasjonenes ærend, blir det også uklare grenser mellom normalitet og patologi.

\section{Idrettspsykologi og idrettspsykiatri}

Idrettspsykologi ble etablert som disiplin i forrige århundre, også i Norge. I denne tradisjonen arbeides det målrettet med psykologiske teknikker for å fremme idrettslig prestasjon. I idrettspsykiatri er det ikke prestasjonen, men mennesket og helsen som er fokus.

Det har generelt vært lite søkelys på psykiske lidelser innenfor den organiserte idretten. Det kan være flere grunner til dette. Filosofen Paul Weiss beskriver i boken Sport: A philosophic inquiry atleten som «excellence in the guise of men» (2). Slik idealisering av utøvere kan bidra til forestillinger om lav prevalens av psykiske lidelser og at omgivelsene overser tegn og symptomer. Det er mitt klare inntrykk at støtteapparatenes kompetanse til å se slike tegn er høyst variabel. Dette gjelder også i idrettens egne medisinske team, da idrettsmedisin tradisjonelt retter seg mot somatikk.

Idrettskulturen har ikke vært i første rekke for å bekjempe tabuiseringen av psykiske lidelser. Utøveren kan selv være en som rapporterer lite og har normer om å tåle i stedet for å si ifra. Eller han/hun kan frykte praktiske konsekvenser som reservebenken. At det rapporteres lite, kan også skyldes at den kroppsorienterte idrettskulturen mangler språk om sinnets smerter. Det kan være flytende overganger mellom idrettslig atferd og psykiske symptomer. For eksempel: Brukes aktivitet mest for prestasjon eller for å dempe indre uro? Hva er grensegangene mellom sterkt fokus på ernæring og symptomer på spiseforstyrrelse? Hva er «å være tent» og hva er aggresjon og dårlig følelsesregulering?

Idrettspsykiatri beskrives her som en ikke-formalisert grenspesialitet både i psykiatri og idrettsmedisin. Fagfeltet er svakt forankret som akademisk tradisjon,

\section{«Det har generelt vært} lite søkelys på psykiske lidelser innenfor den

\section{organiserte idretten»}

og det er et åpenbart behov for forskning. Det gjelder økt kunnskap for å beskrive og forstå denne spesifikke populasjonen, men også at erfaringer fra idrett, som sammenhenger mellom fysisk aktivitet og psykisk helse, kan være relevante i et allment helseperspektiv.

I denne artikkelen beskrives fagfeltets unge historie, idrettens psykopatologi og intervensjoner. Kildegrunnlaget er idrettspsykiatrisk litteratur innhentet gjennom søk i medisinske databaser, deltakelse i cybernettverket til International Society for Sport Psychiatry, foruten forfatterens egne erfaringer som psykiater på deltid i Olympiatoppen i 15 år.

\section{Idrettspsykiatriens korte historie}

Det er grunn til å fremheve tre amerikanske psykiatere. De skrev alle innenfor den psykodynamiske tradisjonen. Arnold Beisser (1925-91) var en pioner med sitt psykiatriske blikk på idrettsutøvere i boken The madness in sports fra 1967 (3). I sine unge år var han en høyt ranket tennisspiller, men ble alvorlig rammet av polio. Dette er en samling av kliniske studier av utøvere som har lagt opp. Han beskriver psykiske symptomer, blant annet depresjon, hos atleter som har mistet idretten. Boken er rik på kliniske detaljer og idéhistorisk forankret i tekstene til psykoanalytikere som Sigmund Freud, Erik H. Erikson og Heinz Kohut.

En viktig begivenhet i idrettspsykiatrien var da Daniel Begel fikk publisert artikkelen An overview of sport psychiatry i 1992 (4). Her definerer han et rammeverk for fagfeltet og presenterer en rekke kasuistikker. Han har et utviklingspsykologisk perspektiv på hva idrett kan bety i forskjellige faser av barns, unges og voksnes liv og anlegger et psykodynamisk perspektiv på idrettspsykiatriske problemer. Han beskriver en rekke risikoforhold, som medienes og publikums hang til å dyrke og forkaste sine nasjonale idoler, og trekker frem spesifikke lidelser, som eksempelvis anorexia nervosa. Begel beskriver også psykoterapi for atleter og advarer mot risikoen for at idrettsinteresserte terapeuter i motoverføring lar profesjonelle rammer flyte ut når de arbeider med sine helter. Begel er også ansvarlig for den første boken som definerer fagfeltet (5).

Barnepsykiateren Ian Tofler har bidratt betydelig til diskusjonen om idrettens mulige betydninger i barns og unges oppvekst (6). Han er særlig opptatt av hvordan foreldre kan leve ut egne ambisjoner gjennom barnas idrettslige aktiviteter. Tofler anvender den sveitsiske psykoanalytikeren og forfatteren Alice Millers beskrivelser av «det begavete barns drama» når han diskuterer hvordan foreldre kan anvende sine barn for egen narsissistisk tilfredsstillelse (7). Millers og Toflers poeng er at når barnet på denne måten blir et redskap for foreldrene, skiller ikke foreldrene mellom egne behov og barnets behov. Det vil kunne hemme barnets sunne selvutvikling. Med utgangspunkt i diagnosen Münchausen by proxy, som er en beskrivelse av foreldre som påfører sine barn helseskade, definerte Tofler «achievement by proxy».

For å fremme fagfeltet klinisk og akademisk ble International Society for Sport Psychiatry etablert i 1994, initiert av Daniel Begel. Det er åpent for medlemskap for psykiatere og andre faggrupper fra hele verden, men aktivitetene har en sterk nordamerikansk forankring. I norsk sammenheng handler idrettspsykiatrisk virksomhet først og fremst om et begrenset antall psy- 


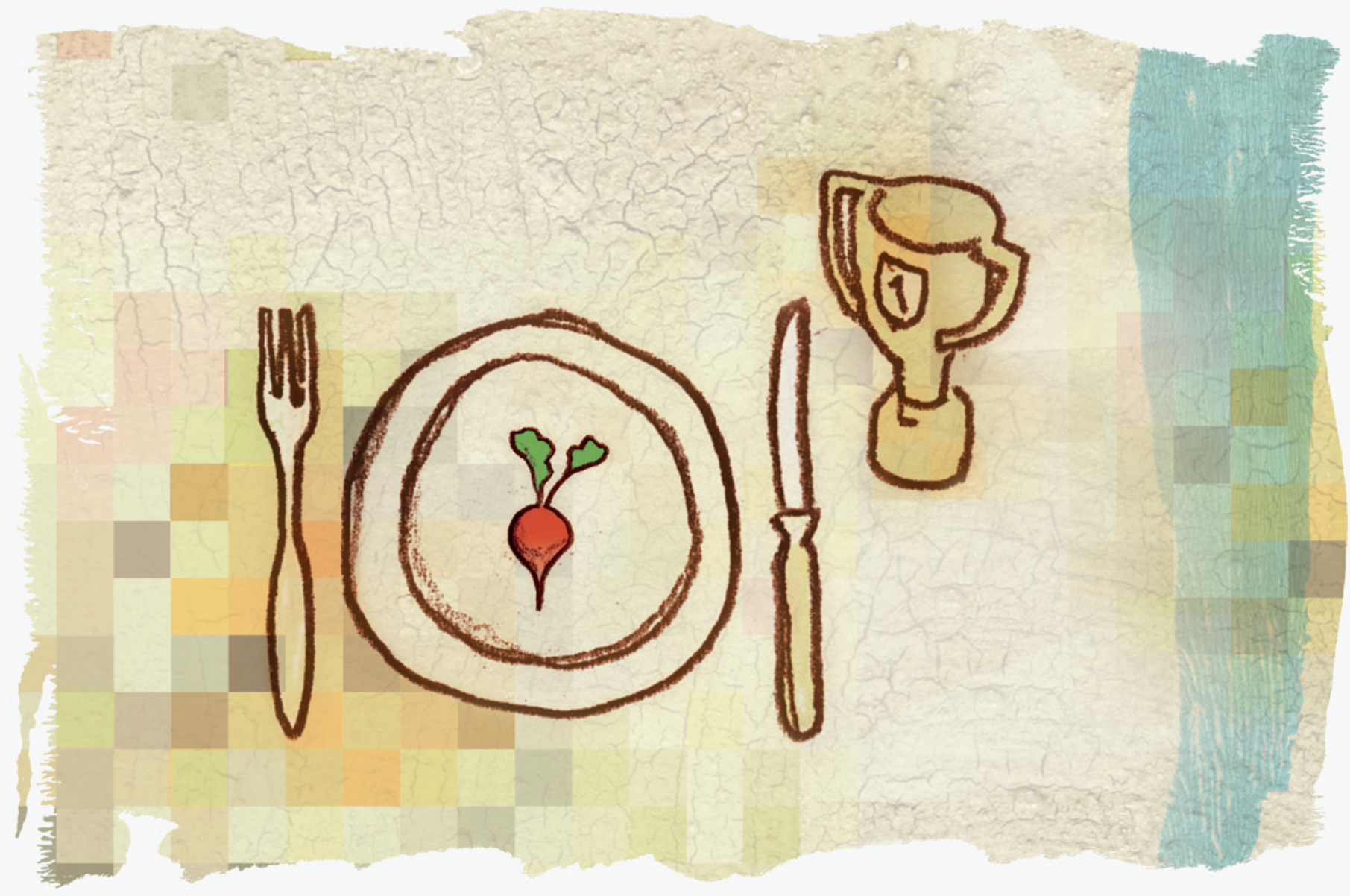

kiatere og kliniske psykologer som med tilknytning til toppidrettsmiljøer driver klinisk praksis. Leif Roar Falkum, tidligere høydehopper, var den første psykiateren som ble knyttet til Olympiatoppen på Toppidrettssenteret i Oslo. Han fungerte som konsulent og terapeut for toppidrettsutøvere i ti år. Undertegnede tok over liknende funksjoner i 1998.

I norsk og internasjonal sammenheng har det vært - og er - mye oppmerksomhet rundt varianter av spiseforstyrrelser, patologisk spiseatferd og kroppsbildeforstyrrelser, tidligere omtalt i Tidsskriftet (8). Ved Olympiatoppen i Oslo har det i flere år vært et eget tverrfaglig team rettet mot spiseforstyrrelser. Psykiske belastinger i toppidrett er behandlet i debattboken Toppidrett (9).

\section{Idrettens psykopatologi}

Klinisk erfaring tilsier at det finnes flere relasjoner mellom idrett og psykiatri. Reardon \& Factor foreslår følgende tre mulige forhold (10):

- Utøveren kan prestere godt til tross for samtidige psykiske lidelser

- Utøveren kan ha valgt idretten som en arena for mestring av lidelse

- Deltakelse i idrett forverrer psykisk lidelse
Personer bringer med seg sin personlighet, historie og sårbarhet til idrettsarenaene. Anlegg for psykisk lidelse kan omformes til normalfungering. Personlighetstrekk som er dysfunksjonelle i visse sammenhenger, kan være mer funksjonelle innenfor visse idrettsgrener, for eksempel kampsporter. For andre kan det være slik at deltakelse i idrett i seg selv er risikofaktorer.

Toppatleten står i en særstilling. På et vis tilhører kropp og sinn andre, slik som idrettsledere, sponsorer, publikum og medier. Treners og foreldres glede - kanskje også økonomi - legges på utøverens skuldre. Man er gjenstand for andres projeksjoner og et begjærsobjekt. Selvet kan overbelastes av forventninger om å tilfredsstille andre. I gode tider kan det oppleves som en eufori, og han eller hun blir næret av narsissistisk bekreftelse. Men om man ikke er trygg i seg selv, kan man kjenne avhengigheten av de andres anerkjennelse (9). Fra egen praksis har jeg sett risikoen ved at selvfølelse er ensidig sterkt forankret i de idrettslige prestasjonene. Et ungdomsliv viet til idrett kan hemme den mer allmenne sosialiseringen.

Skader eller overtrening kan medføre risiko. For noen betyr skadeperioden mang- lende muligheter for å agere ut indre uro. For andre kan det bety vektøkning, som igjen kan sette i gang risikable prosjekter for vektreduksjon. Store treningsmengder kan ha både fysiske og psykiske konsekvenser (11). Kanskje opptil et par hundre reisedøgn er i seg selv anstrengende og en belastning for parforhold og familiesituasjon. En del utøvere erfarer dessverre manglende kompetanse hos trenere eller ledere, bl.a. krenkende kommentarer og aggresjon. Seksuelle krenkelser er også en aktuell tematikk. Et toppidrettsliv betyr et meget sterkt fokus på kropp. I kombinasjon med tette relasjoner og mye tid sammen på reise og hoteller kan dette bidra til uklare grenser (12).

Tilsvarende kan man tenke seg beskyttelses- eller resiliensfaktorer. Mange utøvere erfarer gode sosiale fellesskap med medutøvere og støtte og oppmerksomhet fra trenere og ledere. Idrettslivet kan bidra med spenning, opplevelser, triumfer, mening, fokus og ikke minst organiserende strukturer - og altså gleden over å mestre. For noen kan det være slik at idretten har vært et alternativt og støttende miljø, til forskjell fra eksempelvis et hjem med rus. 


\section{Stemningslidelser og angst}

Reardon \& Factor redegjorde i 2010 for synlighet og forekomster av forskjellige diagnosegrupper (13). Stemningslidelser og angstlidelser er både allmennpopulasjonens og idrettens mest frekvente lidelser. Som det ble beskrevet av Beisser allerede i 1967 (3), er det å legge opp en risikofaktor.

Når det gjelder angstspektrumlidelser, har det vært særlig mye oppmerksomhet rettet mot prestasjonsangst. Dette er et naturlig fenomen, men kan anta patologiske dimensjoner. Angst er også beskrevet i tilknytning til skader. For noen kan et idrettsliv med ritualistisk trening likne på tvangslidelser (obsessive-compulsive disorder).

\section{Spiseforstyrrelser og selvskading}

Som nevnt er mye oppmerksomhet rettet mot varianter av spiseforstyrrelser og patologisk spiseatferd. I en norsk studie fant man at $20 \%$ av kvinnelige toppidrettsutøvere hadde symptomer på spiseforstyrrelser, mot $9 \%$ i en kontrollgruppe av ikkekonkurrerende kvinner (13). Det er spiseforstyrrelser i alle idrettsgrener, men hyppigst i estetiske idretter, vektklasseidretter og utholdenhetsidretter (8). Spiseforstyrrelser og selvskading forekommer ikke sjelden samtidig $(14,15)$.

\section{Alkohol, rus og doping}

I egen praksis har jeg møtt mange utøvere med misbruksproblemer. Fra amerikanske universiteter finnes det flere studier om bruk og misbruk av rusmidler, og tendensen er at bruken av alkohol der er større enn i den amerikanske normalpopulasjonen (10).

Mitt inntrykk er at doping er et tilnærmet ikke-eksisterende problem i norsk idrettspsykiatrisk praksis. Doping synes nå å handle lite om konkurranseidrett og desto mer om fitness, machokultur og blandingsmisbruk av dop og narkotika $(16,17)$.

\section{AD/HD og personlighetsforstyrrelse}

Det er hevdet at forekomsten av AD/HD er høyere i idrett enn i normalpopulasjonen, men det finnes ikke empirisk kunnskapsgrunnlag for dette (10). Tesen er at urolige mennesker finner rom og uttrykk for sin hyperaktivitet gjennom aktiviteter og atferd og derfor har søkt seg til idrett. Jeg har ikke lyktes med å finne studier av forekomster av forskjellige former for personlighetsforstyrrelser innenfor idrett og toppidrett.

\section{Terapi og tiltak}

Mens idrettspsykologiens rasjonale er å fremme prestasjoner, er det bedret mental helse som står i fokus i idrettspsykiatrisk praksis. Gjennom årene har undertegnede ved Olympiatoppen flere ganger erfart at bedret helse best oppnås ved å tre ut av konkurranseidrett.
Det psykoterapeutiske tilbudet ved Olympiatoppen representerer kombinasjoner av psykodynamisk og kognitiv psykoterapi. Den vanligste formen er individualterapi, i en del tilfeller også langtidsterapi over flere år. Men det kan også innebære familieterapi. Jeg har også erfaringer med gruppepsykoterapi for kvinnelige topputøvere med spiseforstyrrelser.

Det er evidens for at psykoterapi er den mest effektive behandlingen ved spiseforstyrrelser generelt (18). En praktisk utfordring er idrettslivenes sterke vektlegging av det konkrete. Idrettssosiolog Jan Ove Tangen beskriver toppidrett som kvantifisering, kalkulering, standardisering og disiplinering (19). Til forskjell fra pasienten som aktivt søker seg til psykoterapeutisk hjelp, kan det $\mathrm{i}$ arbeidet med noen utøvere kreve ekstra innsats for å fremme en kultur for undring og mentalisering.

Ved forskrivning av psykofarmaka til idrettsutøvere må de enkelte preparatene sjekkes med dopinglisten til World AntiDoping Agency (WADA).

Tverrfaglige team står helt sentralt i idrettspsykiatrisk praksis. Utøvere på høyt nivå har en «storfamilie» av trenere, ledere og hjelpere. Det er viktig å arbeide for et minstemål av felles forståelse, enighet om tiltak og klarhet $\mathrm{i}$ hvem som snakker med hvem om hva. Det oppfordres generelt til mye åpenhet, men som helsepersonell forholder vi oss selvfølgelig alltid til taushetsplikten. I en rekke sammenhenger arbeides det også sammen med det idrettspsykologiske fagmiljøet. Vi har gode erfaringer med mer omfattende intervensjoner i landslag, hvor et tverrfaglig team inkludert psykiateren arbeider systematisk med utøvere, trenere og ledere, både individuelt og med det samlede laget, for å fremme bedre lagkultur, helse og til sist bedre prestasjoner.

Innenfor hele idrettskulturen er det behov for å fremme kunnskap om sinnets helse generelt, men også om idrettsspesifikke utfordringer. Prosjektet Sunn jenteidrett (20) er et eksempel på kompetansefremmende arbeid. Dette er et lavterskeltilbud med en telefontjeneste for rådgivning. Et annet konkret tiltak er Olympiatoppens utdanningsprogram for sertifisering som toppidrettstrener der idrettspsykiatri er en egen modul (21).

\section{Finn Skårderud (f. 1956) er spesialist}

i psykiatri, dr.med. og professor ved Institutt for spesialpedagogikk, Universitetet i Oslo, overlege ved Oslo universitetssykehus og jobber deltid som psykiater ved Olympiatoppen i Oslo. Forfatter har fylt ut ICMJE-skjemaet og oppgir ingen interessekonflikter.

\section{Litteratur}

1. Martinsen EW. Kropp og sinn. Fysisk aktivitet psykisk helse, kognitiv terapi. Bergen: Fagbokforlaget, 2011.

2. Weiss P. Sport: A philosophical inquiry. Carbondale, IL: Southern University Press, 1969.

3. Beisser A. The madness in sports. New York, NY: Appleton-Century-Crofts, 1967.

4. Begel D. An overview of sport psychiatry. Am J Psychiatry 1992; 149: 606-14

5. Begel D, Burton, RW, red. Sport psychiatry theory and practice. New York, NY: W.W. Norton \& Company, 2000

6. Tofler IR, Knapp PK, Drell MJ. The «achievement by proxy» spectrum: recognition and clinical response to pressured and high-achieving children and adolescents. J Am Acad Child Adolesc Psychiatry 1999; 38: 213-6.

7. Miller A Barneskjebner. Oslo: Gyldendal, 1980.

8. Sundgot-Borgen J, Klungland M, Skårderud F. Spiseforstyrrelser i idretten. Tidsskr Nor Lægeforen 2004: 214: 2126-9.

9. Skårderud F. Portrett av atleten i nød. I: Loland S, red. Toppidrettens pris. Oslo: Universitetsforlaget, 1998: 71-88

10. Reardon CL, Factor RM. Sport psychiatry: a systematic review of diagnosis and medical treatment of mental illness in athletes. Sports Med 2010; 40 961-80.

11. Purper-Ouakil D, Michel G, Baup N et al. Aspects psychopathologiques de l'exercice physique intensif chez l'enfant et l'adolescent: mise au point à partir d'une situation clinique. Ann Med Psychol (Paris) 2002; 160: 543-9.

12. Marks S, Mountjoy M, Marcus M. Sexual harassment and abuse in sport: the role of the team doctor. Br J Sports Med 2011.

13. Sundgot-Borgen J, Torstveit MK. Prevalence of eating disorders in elite athletes is higher than in the general population. Clin J Sport Med 2004; 14: $25-32$

14. Skårderud F. Selvskading og idrett - en kasuistisk tilnærming. Tidsskr Nor Legeforen 2009; 129 . 888-90.

15. Skårderud F, Sommerfeldt B. Selvskading og spiseforstyrrelser. Tidsskr Nor Legeforen 2009; 129: 877-81.

16. Barland B, Tangen JO. Kroppspresentasjon og andre prestasjoner. En omfangsundersøkelse om bruk av doping. PHS Forskning 2009: 3. Oslo: Politihøgskolen, 2009

17. Barland B, Tangen JO, Johannesen CA. Doping. Muskler, mestring og mening. En kvalitativ studie av unge menns bruk av muskelbyggende medikamenter. PHS Forskning 2010: 6. Oslo: Politihøgskolen, 2010.

18. Skårderud F, Rosenvinge JH, Götestam KG. Spiseforstyrrelser. En oversikt. Tidsskr Nor Lægeforen 2004; 124: 1938-42

19. Tangen JO. Idrettens patologiske trekk: Tilfeldighet eller konsekvens? Kroppsøving 1988: nr. 4 : $15-21$.

20. Sunn jenteidrett. www.sunnjenteidrett.no (10.8.2012).

21. Olympiatoppen. Coaching. www.olympiatoppen.no/ fagomraader/coaching/page846.html (10.8.2012).

Mottatt 8.4. 2012, første revisjon 10.8. 2012, godkjent 16.8. 2012. Medisinsk redaktør Siri Lunde. 